\title{
TRANSDERMAL DELIVERY OF CALCIUM CHANNEL BLOCKER: DEVELOPMENT AND CHARACTERIZATION
}

\author{
SURYA TEJA SP, MANISHA KHANDELWAL, CHITRA V, DAMODHARAN N* \\ Department of Pharmaceutics, SRM College of Pharmacy, SRM University, Kattankulathur, Chennai, Tamil Nadu, India. \\ Email: damodharan.n@ktr.srmuniv.ac.in
}

Received: 27 October 2016, Revised and Accepted: 27 April 2017

\section{ABSTRACT}

Objective: Felodipine, a BCS class II calcium channel blocker, is used in the management of hypertension and angina pectoris. Due to the poor solubility and low bioavailability of the drug, there is a necessity to design an alternative route to achieve a constant plasma concentration of felodipine for its maximum therapeutic utility and can be achieved by transdermal route.

Methods: In this study, matrix type transdermal patches were prepared using different combinations of hydrophilic polymer, namely, polyvinylpyrrolidone (PVP) and hydrophobic polymer, namely, ethyl cellulose (EC) by solvent evaporation technique and were subjected for characterization.

Results: The Fourier transform infrared studies confirmed the compatibility between drug and polymers. Hydrophilic nature of the polymers greatly influenced physical characteristics and dissolution rate. Equal percentage of PVP and EC yielded patches with good folding endurance. The concentration of plasticizer present in the patches gave them desired folding endurance, and it increased with the presence of hydrophilic polymer. The formulation with highest PVP concentration, F3, exhibited a maximum drug release of $96.23 \%$ for 24 hrs. While the formulation with highest EC concentration, F5, exhibited only $74.45 \%$ drug release for 24 hrs.

Conclusion: From the data, formulation F2 (PVP/EC, 2:1) can be concluded as best formulation due to its desired physical characteristics, good initial drug release, sustained release behavior, and good in vitro permeation. This formulation can be further studied in a clinical scenario.

Keywords: Calcium channel blocker, Felodipine, Transdermal, Permeation.

(C) 2017 The Authors. Published by Innovare Academic Sciences Pvt Ltd. This is an open access article under the CC BY license (http://creativecommons. org/licenses/by/4. 0/) DOI: http://dx.doi.org/10.22159/ajpcr.2017.v10i8.15910

\section{INTRODUCTION}

Sustained release preparations were developed intended to provide prolonged drug release than the conventional dosage forms. In prolonged treatment of hypertension (high blood pressure), they are highly recommended and commercially available mostly in the form of conventional tablets [1]. An approach to sustained delivery of a therapeutically active agent is transdermal drug delivery system [2]. They provide relatively constant plasma drug concentrations, avoiding the peaks and valleys associated with conventional dosage forms. They also offer advantages such as decrease in frequency of administration, avoiding first-pass metabolism, reducing gastrointestinal side effects, and improving patient compliance [3]. Skin is the most magnanimous and readily accessible organ of human body and is used as an administration site of drug for both local and systemic actions; the highly organized structure of stratum corneum forms an effective barrier to the permeation of poorly penetrating drugs [4-6].

Felodipine, BCS class II drug, a calcium channel blocker is primarily used to treat hypertension and also used in the treatment of angina, arrhythmia, and coronary vasospasm [7]. It acts by inhibiting the influx of calcium in smooth muscle cells and prevents calcium-dependent myocyte contraction and vasoconstriction. Due to its low bioavailability and short half-life, it needs to be frequently administered creating patient incompliance [8]. It possesses ideal characteristics for being formulated as transdermal patch, such as low molecular weight (384.25), low dose (5 mg), and low solubility and bioavailability (15\%), and undergoes extensive first-pass metabolism [9].

The objective of the present study is to fabricate a novel transdermal delivery system for treating hypertension, which achieves a prolonged drug release and effective management of hypertension, while at the same time by reducing the frequency and dose of administration. The objective includes designing more patient friendly delivery system of felodipine for sustained release using a combination of hydrophilic and hydrophobic polymers.

\section{MATERIALS AND METHODS}

Materials

Felodipine was obtained from Orchid Chemicals and Pharmaceuticals Ltd. as a gift sample. Ethyl cellulose (EC), polyvinylpyrrolidone (PVP), and polyvinyl alcohol (PVA) were procured from Sigma Aldrich, Mumbai, India, and all other chemicals and reagents used were of analytical grade.

\section{Determination of partition coefficient}

Shake-flask method was employed to determine the partition coefficient of the drug using n-octanol and phosphate buffer $\mathrm{pH} 7.4$ as oil and water phases, respectively. Equal quantities of two phases were taken in a separating funnel. A known quantity of felodipine was added and shaken for 10 minutes and allowed to stand for an hour. Aqueous and oil phases were separated and filtered through Whatman filter paper. The samples were analyzed for drug content in each phase. The partition coefficient $\mathrm{k}_{\mathrm{o} / \mathrm{w}}$ was calculated using the formula. Triplicate reading was taken, and average was calculated $[10,11]$.



Infrared spectral analysis

Compatibility studies of felodipine and the polymers were carried out using Fourier transform infrared (FTIR) spectroscopy. Spectroscopy of 
the samples was obtained in the range of $4000 / \mathrm{cm}$ to $400 / \mathrm{cm}$ using a PerkinElmer-FTIR 8201 PC spectrophotometer by the KBr disc method [12].

\section{Preparation of transdermal patches}

Different ratios (Table 1) of PVP and EC were taken in the open-ended cylindrical glass molds to prepare the matrix type transdermal patches of felodipine. Backing membrane was cast by pouring $4 \% \mathrm{w} / \mathrm{v}$ of PVA solution in the molds previously wrapped with aluminum foil. It was allowed to dry at $60^{\circ} \mathrm{C}$ in hot air oven for $6 \mathrm{hrs}$. The two polymers were taken in requisite ratio and dissolved in chloroform. Di-n-butyl phthalate was taken in $30 \% \mathrm{w} / \mathrm{w}$ of polymer composition and used as plasticizer. Drug was added, $20 \% \mathrm{w} / \mathrm{w}$ of polymer composition, to form homogenous dispersion with plasticizer and polymers. Three milliliters of dispersion were cast on previously prepared PVA backing membrane and dried at $40^{\circ} \mathrm{C}$ for $6 \mathrm{hrs}$. The prepared patches were kept in desiccators until used [13].

\section{Thickness}

Thickness of both the backing membrane and patch was measured using digital calipers. The average thicknesses of the backing membrane and the whole patch were determined $[14,15]$. The average thickness of the adhesive matrix containing the drug was determined using the following equation:

Thickness of adhesive matrix=Thickness of whole patch-Thickness of backing membrane

\section{Moisture content}

The prepared patches were weighed individually and kept in a desiccator containing activated silica at room temperature for $24 \mathrm{hrs}$. The individual films were weighed again until it showed a constant weight [16]. The percentage of moisture content was calculated as:

$$
\% \text { Moisture content }=\frac{\text { Intail wt of thefilm }- \text { Final wt of thefilm }}{\text { Initialwt of thefilm }} \times 100
$$

\section{Moisture uptake}

The patches were weighed and kept in a desiccator at normal room temperature for $24 \mathrm{hrs}$. This patch was taken out and exposed to $84 \%$ RH (saturated solution of potassium chloride) in a desiccator. After 3 days, the patches were taken out and weighed [17]. The percentage of moisture uptake was calculated as:

$$
\% \text { Moistureuptake }=\frac{\text { Final wt of the film }- \text { Initial wt of the film }}{\text { Initial wt of thefilm }} \times 100
$$

\section{In vitro drug release study}

In vitro drug release study was performed using US Pharmacopeia Type V dissolution apparatus (Paddle over disc). The patches were placed in between the stainless steel discs (of which one side is mesh and one side is plate stainless steel disc, meant for transdermal study). To the stainless steel plate, the backing membrane was attached with a double-sided adhesive tape so that drug releases from one side only. The drug release study was performed at $37 \pm 0.5^{\circ} \mathrm{C}$ and 50 in dissolution jar holding $900 \mathrm{ml}$ of $20 \% \mathrm{v} / \mathrm{v}$ polyethylene glycol (PEG) 400 in normal saline as dissolution medium. A $5 \mathrm{ml}$ of sample was withdrawn at regular time intervals and replaced with $5 \mathrm{ml}$ of $20 \% \mathrm{v} / \mathrm{v}$ PEG400 in normal saline. The samples were analyzed to calculate the quantity of drug released. The mean cumulative amount of drug released of patch was plotted against time [18]

\section{Ex vivo permeation}

Franz diffusion cell was used to study the permeation of transdermal patch. Full thickness of rat abdominal epidermis was mounted onto a Franz diffusion cell. Place the patch in such a way that stratum corneum side of rat skin was in contact with transdermal patch in the donor compartment and the dermis side was in constant contact with the receptor solution. The receptor compartment was filled with $20 \% \mathrm{v} / \mathrm{v}$ PEG 400 in normal saline and stirred magnetically. A $1 \mathrm{ml}$ of sample was withdrawn at different time intervals and analyzed for drug content and replaced with an equal volume of $20 \%$ v/v PEG 400 in normal saline at each time interval. The cumulative amount of drug permeated was calculated for $12 \mathrm{hrs}$ and plotted against time [19]

\section{Statistical analysis}

All data were represented as the mean \pm standard deviation. The graphs and error bars were depicted using GraphPad Prism 5 software (GraphPad Software, Inc., San Diego, CA).

\section{RESULTS AND DISCUSSION}

To determine the drug partition coefficient between skin and in vitro study fluid, octanol and phosphate buffer $\mathrm{pH} 7.4$ were considered to be a standard system. The studies were conducted in triplicate. The mean value of all these experiments was considered as partition coefficient. The $\log \mathrm{P}$ of felodipine was found to be 4.46 . The $\log \mathrm{P}$ clearly indicates that felodipine possesses optimum lipophilic nature to be formulated into a transdermal delivery system.

The spectrum of pure drug shows absorption band at $3389 / \mathrm{cm}$ due to the stretching $\mathrm{N}-\mathrm{H}$ group of dihydropyridine moiety. The band between $2946 / \mathrm{cm}$ and $3070 / \mathrm{cm}$ was due to stretching aromatic and aliphatic C-H bond. The absorption band at $1694 / \mathrm{cm}$ can be attributed to carbonyl group present on the side chain of dihydropyridine moiety. The band at $1495 / \mathrm{cm}$ was due to aromatic $\mathrm{C}=\mathrm{C}$ bond. The bands present at $1204 / \mathrm{cm}$ indicate $\mathrm{C}=0$ stretching. The spectrum of the mixture showed that they were in good agreement with the spectra of felodipine. Thus, from the spectra in Fig. 1, it was understood that there was no significant interaction between felodipine and polymers used in the preparation of transdermal patches.

PVP and EC combination was also preferred in preparation of transdermal patches for sustaining the release of diclofenac [20]. The transdermal patches for felodipine were analyzed for various physical characterizations such as moisture content, moisture uptake, thickness, and folding endurance. The summary of the characterization parameters was given in Table 2. The moisture content and moisture uptake studies on patches revealed that an increase in the concentration of PVP resulted in high moisture content and high moisture uptake ability (Fig. 2)

On the other hand, the formulations exhibited, increasing the EC proportion resulted in patches with low moisture uptake ability. This can be attributed to the hydrophilic nature of PVP and hydrophobic

Table 1: Formulation of transdermal patches

\begin{tabular}{llllll}
\hline Formulation code & Ratio of PVP:EC & $\begin{array}{l}\text { Total weight of PVP } \\
\text { and EC ( } \mathbf{m g})\end{array}$ & Chloroform (m) & $\begin{array}{l}\text { Di-n-butyl } \\
\text { phthalate (ml) }\end{array}$ & Felodipine (mg) \\
\hline F1 & $1: 1$ & 250 & 10 & $30 \%$ w/w of polymers & $20 \%$ w/w of polymers \\
F2 & 250 & 10 & $30 \%$ w/w of polymers & $20 \%$ w/w of polymers \\
F3 & $5: 1$ & 250 & 10 & $30 \%$ w/w of polymers & $20 \%$ w/w of polymers \\
F4 & $1: 2$ & 250 & 10 & $30 \%$ w/w of polymers & $20 \%$ w/w of polymers \\
F5 & $1: 5$ & 250 & 10 & $30 \%$ w/w of polymers & $20 \%$ w/w of polymers \\
\hline
\end{tabular}

PVP: Polyvinylpyrrolidone, EC: Ethyl cellulose 
Table 2: Physical characterization of transdermal patches

\begin{tabular}{lllll}
\hline Formulation code & Folding endurance* & Thickness* $^{*}(\mathbf{m m})$ & Percentage moisture content* $^{*}$ (\%) & Percentage moisture uptake* (\%) $^{\text {Pen }}$ \\
\hline F1 & $177 \pm 12$ & $0.189 \pm 0.25$ & $5.90 \pm 0.10$ & $11.28 \pm 0.01$ \\
F2 & $189 \pm 31$ & $0.201 \pm 0.98$ & $7.36 \pm 0.12$ & $12.33 \pm 0.12$ \\
F3 & $223 \pm 15$ & $0.240 \pm 0.23$ & $8.01 \pm 0.05$ & $16.91 \pm 0.05$ \\
F4 & $171 \pm 18$ & $0.199 \pm 0.73$ & $3.46 \pm 0.29$ & $6.38 \pm 0.26$ \\
F5 & $169 \pm 09$ & $0.233 \pm 0.59$ & $1.28 \pm 0.06$ & $4.79 \pm 0.21$ \\
\hline
\end{tabular}

*Data were presented as mean \pm standard deviation $(\mathrm{n}=6)$

Table 3: In vitro dissolution profile of transdermal patches

\begin{tabular}{lllll}
\hline Time (hrs) & \multicolumn{4}{l}{ Cumulative drug release (\%) } \\
\cline { 2 - 5 } & F1 & F2 & F3 & F4 \\
\hline 0.5 & $6.02 \pm 1.13$ & $12.21 \pm 1.51$ & $15.60 \pm 1.09$ & $4.25 \pm 1.83$ \\
1 & $12.08 \pm 2.26$ & $23.02 \pm 1.62$ & $24.21 \pm 1.50$ & $11.56 \pm 1.12$ \\
2 & $29.23 \pm 1.39$ & $37.29 \pm 1.43$ & $34.23 \pm 1.46$ & $19.24 \pm 1.72$ \\
4 & $36.89 \pm 1.42$ & $41.35 \pm 2.30$ & $53.24 \pm 1.77$ & $32.29 \pm 2.38$ \\
8 & $50.35 \pm 2.16$ & $54.24 \pm 1.19$ & $68.03 \pm 3.33$ & $48.89 \pm 1.55$ \\
12 & $62.64 \pm 2.96$ & $76.21 \pm 1.25$ & $79.56 \pm 2.17$ & $53.32 \pm 1.42$ \\
24 & $80.24 \pm 1.48$ & $92.37 \pm 2.19$ & $96.23 \pm 2.28$ & $43.09 \pm 1.61$ \\
\hline
\end{tabular}

Data were presented as mean \pm standard deviation $(n=6)$

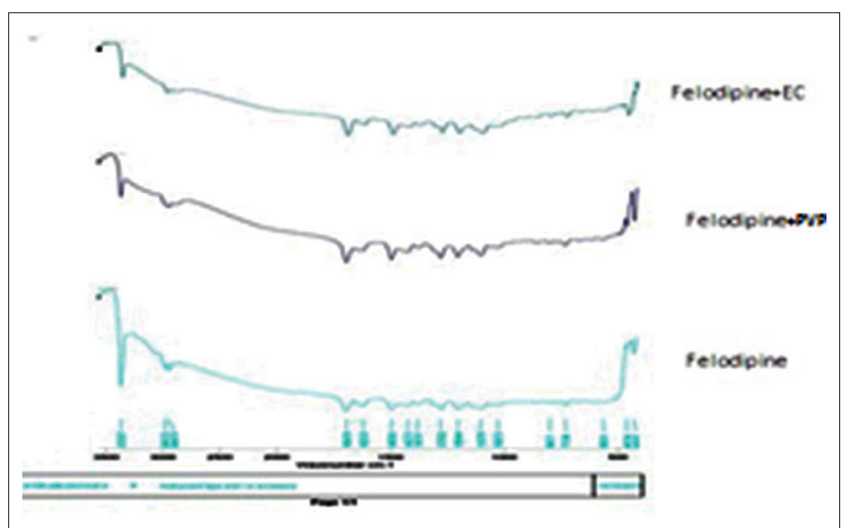

Fig. 1: Fourier transform infrared spectra of felodipine and physical mixtures

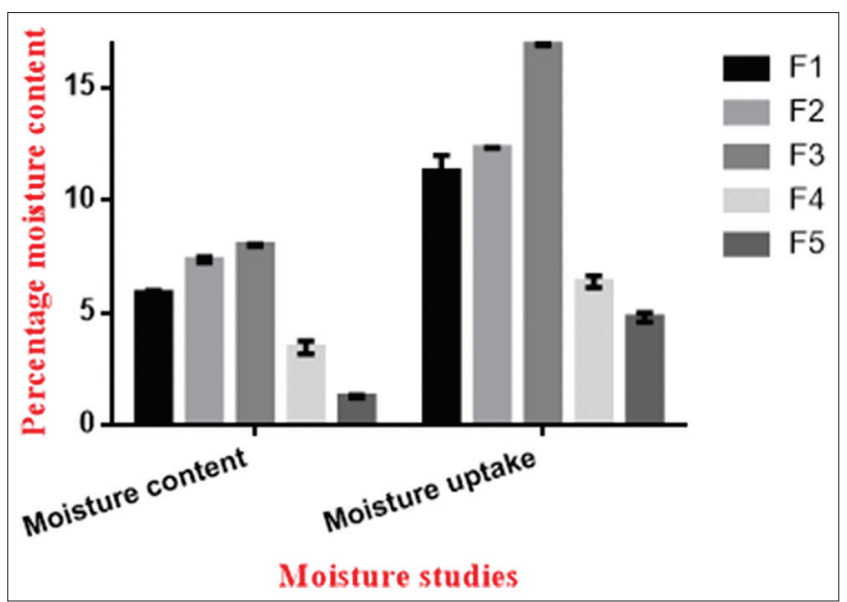

Fig. 2: Moisture studies on transdermal patches. Data are presented as mean \pm standard deviation $(n=6)$

nature of EC. At the same time, the patches with more PVP percentage also seen to be thicker than that of patches with more EC percentage. Low moisture content in the formulations maintains the stability and protects the film from being completely dried. It also protects the patches from being susceptible to microbial contamination and also yields thin patches [21]. The patches with high moisture content were
Table 4: Ex vivo skin permeation studies

\begin{tabular}{ll}
\hline Formulation & Percentage cumulative drug permeated (\%) \\
\hline F1 & $60.83 \% \pm 1.77$ \\
F2 & $67.37 \% \pm 1.41$ \\
F3 & $76.83 \% \pm 2.17$ \\
F4 & $50.27 \% \pm 1.84$ \\
F5 & $43.35 \% \pm 1.45$ \\
\hline
\end{tabular}

Data were presented as mean \pm standard deviation $(n=6)$

observed to be bulky and thicker. Thickness of the patch is an important criteria which gives more patient compliance [22]. Weight variation was observed to be negligible and helped to maintain the uniformity of dose. By increasing the percentage of PVP, a higher folding endurance was observed and it decreased with increasing the percentage of hydrophobic polymer (EC). Equal percentage of PVP and EC yielded patches with good folding endurance. The concentration of plasticizer present in the patches gave them desired folding endurance, and it increased with the presence of hydrophilic polymer.

In vitro drug release is an important tool to predict the in vivo behavior of drug [23]. Table 3 shows the release profiles of patches carried out for $24 \mathrm{hrs}$. In the formulation F3, which had highest percentage of PVP, a maximum drug release of $96.23 \%$ was seen at the end of $24 \mathrm{hrs}$. In the formulations, F2 and F3, an initial burst release was observed. PVP reduced the crystalline nature of felodipine and resulted in increased drug release. The rate of release was decreased with decreasing proportion of PVP and increasing proportion of EC. The formulation F5 which contains maximum EC concentration exhibited lowest drug release of $74.45 \%$, and their dissolution profile is depicted in Fig. 3. This clearly indicates the sustained release behavior of EC due to its hydrophobic nature. The patches containing equal amounts of PVP and EC exhibited a good drug release of $80.24 \%$ which can be helpful in maintain a stable plasma concentration.

Ex vivo permeation studies are a predictive assessment of in vivo performance of drug. The cumulative amount of drug permeated after $12 \mathrm{hrs}$ was calculated and was given in Table 4 . A maximum permeation of $76.83 \%$ was observed in the formulation $\mathrm{F} 3$, which had a maximum proportion of PVP. This result clearly indicates that an increase in hydrophilic polymer (PVP) in the patch increases the skin permeation of the drug. Increase in the concentration of hydrophobic polymer (EC) inhibited the drug permeation. This can be clearly noticed from the formulation containing maximum amount of EC, F5, allowed only $43.35 \%$ of drug to permeate after $12 \mathrm{hrs}$ of study. About $60.83 \%$ of drug 


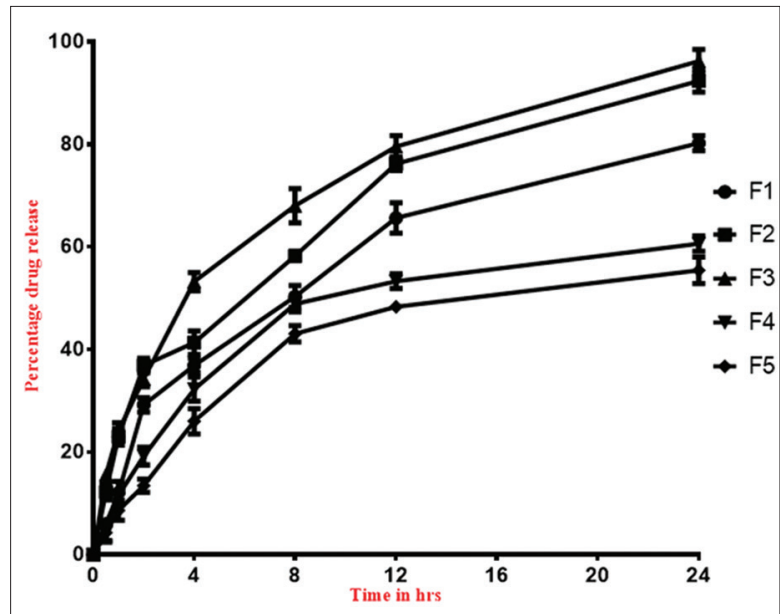

Fig. 3: Dissolution profile of transdermal patches. Data are presented as mean \pm standard deviation $(n=6)$

permeation was seen in the formulation $\mathrm{F} 1$, which had equal proportion of hydrophilic and hydrophobic polymers.

\section{CONCLUSION}

EC and PVP combination can be used to prepare the transdermal patches of felodipine or other calcium channel blockers. The prepared patches are capable of surmounting the low bioavailability factor associated with oral administration of felodipine. From the data, formulation F2 (PVP/EC, 2:1) can be concluded as best formulation due to its desired physical characteristics, sustained release behavior, and good in vitro permeation. This formulation can be further studied in a clinical scenario.

\section{ACKNOWLEGDEMENT}

The authors are thankful to the College of Pharmacy, SRM University, Kattankulathur, Chennai, Tamil Nadu, for their valuable help for carrying out this research work.

\section{REFERENCES}

1. Prausnitz MR, Langer R. Transdermal drug delivery. Nat Biotechnol 2008;26(11):1261-8.

2. Pastore MN, Kalia YN, Horstmann M, Roberts MS. Transdermal patches: History, development and pharmacology. Br J Pharmacol 2015;172(9):2179-209.

3. Anderson DT, Muto JJ. Duragesic transdermal patch: Postmortem tissue distribution of fentanyl in 25 cases. J Anal Toxicol 2000;24(7):627-34.

4. Singh VK, Pokhariyal T, Tiwari AK. Transdermal drug delivery system for non-steroidal anti-inflammatory drugs. Indo Am J Pharm Res
2013;3(5):3588-5.

5. Peter JH, Maisha KF, Terri MW. Appropriate use of transdermal drug delivery systems. J Nurs Educ Pract 2013;3(10):129-38.

6. Alexandra F, Clementina CI, Angela N. The assay of felodipine by second derivative spectrophotometry. Farmacia 2016;64(1):143-6.

7. Santhosh K, Boddeda B. Research on felodipine fast dissolving tablets using solid dispersion. Int J Chem Sci Technol 2012;4(1):223-34.

8. Kumar DS, Reddy A. Formulation and evaluation of mouth dissolving tablets of felodipine. Asian J Pharm Clin Res 2011;4(1):1974-41.

9. Prabhakar D, Sreekanth J, Jayaveera KN. Development and evaluation of transdermal patches of azelnidipine. Int J Pharm Pharm Sci 2013;5(3):805-10.

10. Yadav V. Transdermal drug delivery system: Review. Int J Curr Pharm Res 2012;3(2):376-82.

11. Subramanian S, Rajkapoor B, Vijayaraghavan C. Design and physicochemical evaluation of cetirizine dihydrochloridetransderml patches. Int J Res Pharm Sci 2011;2(3):518-20.

12. Kumar De P, Mallick S, Mukherjee B, Sengupta S, Pattnaik S, Chakraborty S. Optimization of In - vitro permeation pattern of ketorolac tromethamine transdermal patches. Iran J Pharm Res 2011;10(2):193-201.

13. Prabhakar D, Aparna C, Nalini S, Sadanandam M. Development of transdermal patches for bisoprololfumarate. J Pharm Res 2012;5(3):1338-41.

14. Prajapati ST, Patel CG, Patel CN. Formulation and evaluation of transdermal patch of repaglinide. ISRN Pharm 2011;2011:651909.

15. Kapoor D, Vyas RB, Lad C, Patel M, Tyagi BL. Formulation development, optimization and characterization of transdermal patches of dihydropyridine based calcium channel blocker. Int J Inst Pharm Life Sci 2014;4(6):98-7.

16. Sanjoy M, Thimmasetty J, Ratan GN, Kilarimath BH. Formulation and evaluation of carvedilol transdermal patches. Int Res J Pharm 2011;2(1):237-48

17. Mamatha T, Jangala VR, Anitha N. Development and physicochemical, in vitro and in vivo evaluation of transdermal patches of Zaleplon. Indian J Pharm Educ Res 2013;47(4):49-58.

18. Ramkanth S, Alagusundaram M, Gnanaprakash K, Rao KM, Mohammed ST, Paneer K, et al. Design and characterization of matrix type transdermal drug delivery system using metoprolol tartarate. Int $\mathbf{J}$ Pharm Res 2010;1(1):1-5.

19. Deepikareddy H, Rao BB, Shashanka V. Formulation of candesartan cilexetil transdermal patches in-vitro and ex-vivo characterization. Int $\mathrm{J}$ Appl Pharm 2016;6(1):17-22.

20. Priyanka A, Biswajit M. Design, development, physicochemical, and in vitro and in vivo evaluation of transdermal patches containing diclofenac diethylammonium salt. J Pharm Sci 2002;91(9):2076-89.

21. Damodharan N, Gopa R, Soma G, Mukherjee B. Skin permeation of rosiglitazone from transdermal matrix patches. Pharmtech 2010;34(5):56-72.

22. Biswajit M, Kousik S, Gurudutta P, Soma G. Preparation, characterization and in-vitro evaluation of sustained release proteinloaded nanoparticles based on biodegradable polymers. Int J Nanomed 2008:3(4):487-96.

23. Pathan IB, Setty CM. Chemical penetration enhancers for transdermal drug delivery systems. Trop J Pharm Res 2009;8:173-9. 